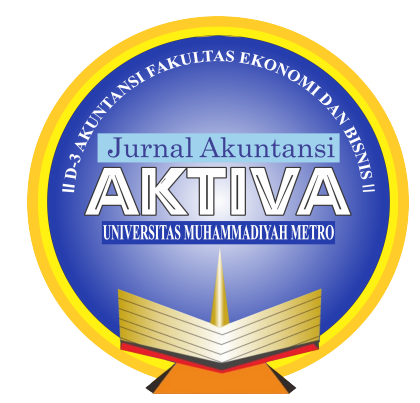

Jurnal Akuntansi AKTIVA Vol 1, No 1, April 2020

\title{
ANALISIS DISIPLIN DAN MOTIVASI KERJA KARYAWAN PADA KSP TRI DHARMA ARTHA DI KANTOR PUSAT SEPUTIH RAMAN
}

\author{
${ }^{1}$ Ni Kadek Dwi Lestari, ${ }^{2}$ Sri Retnaning Rahayu, ${ }^{3}$ Gustin Padwa Sari
}

\begin{abstract}
Universitas Muhammadiyah Metro, J1. Ki Hajar Dewantara, 34111, Lampung, Indonesia Universitas Muhammadiyah Metro, Jl. Ki Hajar Dewantara, 34111, Lampung, Indonesia Universitas Muhammadiyah Metro, J1. Ki Hajar Dewantara, 34111, Lampung, Indonesia
\end{abstract}

Email: nikadekdwilestari93@gmail.com, retnaning27@gmail.com.Gustinpadwasari88@gmail.com

\begin{abstract}
Lestari, Dwi, Kadek 2019, Discipline Analysis and Employee Motivation at KSP Tri Dharma Artha at Seputih Raman Head Office, Final Project, D-III Department of Accounting Study Program, Faculty of Economics and Business, University of Muhammadiyah Metro University, supervisor (1) Sri Retnaning Rahayu , SE, MM Advisor (2) Gustin Padwa Sari, S.E., M.S.Ak.

Employees in a company have a very important role for the progress of the company, because basically employees are the spearhead who run the company, in other words employees are a key source for the company. This study aims to find out how leaders provide motivation to employees at KSP Tri Dharma Artha The method used is a qualitative method. From the results of the study show that motivation is very important for someone considering motivation is an encouragement or motive in individuals that affect certain behaviors, as well as efforts to develop personal life concerned.
\end{abstract}

Keywords: Analysis, Discipline,Motivation

\begin{abstract}
ABSTRAK
Lestari, Dwi, Kadek 2019, Analisis Disiplin Dan Motivasi Kerja Karyawan Pada KSP Tri Dharma Artha Di Kantor Pusat Seputih Raman, Tugas Akhir, Jurusan D-III Program Studi Akuntansi, Fakultas Ekonomi Dan Bisnis Universitas Muhammadiyah Metro, pembimbing (1) Sri Retnaning Rahayu, S.E., M.M. Pembimbing (2) Gustin Padwa, S.E., M.S.Ak.

Karyawan di dalam suatu perusahaan mempunyai peran yang sangat penting bagi kemajuan perusahaannya, karena pada dasarnya karyawan adalah ujung tombak yang menjalankan roda perusahaan dengan kata lain karyawan adalah sumber kunci bagi perusahaan. Penelitia ini bertujuan
\end{abstract}


untuk mengetahui bagaimana pimpinan memberikan motivasi dan terhadap karyawan pada KSP Tri Dharma Artha. Metode yang digunakan adalah metode kualitatif. Dari hasil peneltian menujukan bahwa motivasi sangat penting bagi seseorang mengingat motivasi merupakan dorongan atau motif dalam diri individu yang mempengaruhi tingkah laku tertentu, serta usaha menumbuhkembangkan kehidupan pribadi yang bersangkutan.

Kata Kunci: Analisis, Disiplin, Motivasi

\section{PENDAHULUAN}

Perusahaan baik swasta maupun pemerintah pasti dituntut untuk memaksimalkan kinerja dan memanfaatkan semua sumber daya yang dimiliki, begitupun dengan sumber daya manusianya. Sumber daya manusia merupakan salah satu faktor penting dalam penentuan peningkatan kinerja perusahaan yang harus dapat dikelola dengan sebaik mungkin. Sumber daya manusia merupakan aset yang begitu penting dalam suatu perusahaan, tanpa ada sumber daya manusia perusahaan tidak akan dapat menjalankan roda perusahaan sehingga perusahaan tidak dapat menghasilkan keuntungan/laba.

Menurut kepala SDM KSP Tri Dharma Artha (2019) karyawan di dalam suatu perusahaan mempunyai peran yang sangat penting bagi kemajuan perusahaannya, karena pada dasarnya karyawan adalah ujung tombak yang menjalankan roda perusahaan dengan kata lain karyawan adalahsumber kunci bagi perusahaan. Mengingat pentingnya peran karyawan di dalam perusahaan maka tidaklah berlebihan jika dikatakan karyawan merupakan aset yang penting bagi perusahaan.

Di dalam menjalankan roda suatu perusahaan, perusahaan harus memiliki karyawan yang mempunyai disiplin yang tinggi serta mempunyai motivasi kerja yang tinggi. Kinerja karyawan KSP Tri Dharma Artha di Kantor Pusat Seputih Raman juga dapat diukur melalui penyelesain tugasnya secara efektif dan efesien serta melakukan peran dan fungsinya sesuai tugas masingmasing.

Kedisiplinan dan motivasi merupakan variabel penting yang dapat menentukan kinerja karyawan di suatu perusahaan. Kedisiplinan dapat menentukan jalannya peran, fungsi, dan tujuan yang ada di dalam suatu prusahaan.Rendahnya kinerja karyawan pada KSP Tri Dharma Artha juga terindikasi karna kurangnya disiplin karyawan KSP Tri Dharma Artha, ini dapat dilihat dari seringnya karyawan yang datang terlambat saat jam masuk kerja dan juga banyaknya karywan KSP Tri Dharma Artha yang sering tidak masuk kerja saat hari kerja sehingga mengakibatkan tingginya tingkat absensi karyawan pada KSP Tri Dharma Artha . Tingkat absensi karyawan KSP Tri Dharma Artha ini dapat dilihat pada tabel 1.2 sebagai berikut : 
Tabel 1.2

Tingkat absensi karyawan KSP Tri Dharma Artha Di Kantor Pusat Seputih Raman Tahun 2018

\begin{tabular}{|c|c|c|c|c|c|c|}
\hline Bulan & Tahun & $\begin{array}{l}\text { Jumlah } \\
\text { hari kerja }\end{array}$ & $\begin{array}{l}\text { Jumlah } \\
\text { karyawan }\end{array}$ & $\begin{array}{l}\text { Total hari } \\
\text { kerja }\end{array}$ & $\begin{array}{l}\text { Jumlah hari } \\
\text { absen }\end{array}$ & $\begin{array}{l}\text { Tingkat } \\
\text { absensi }(\%\end{array}$ \\
\hline Januari & 2018 & 21 & 35 & 735 & 43 & $5,85 \%$ \\
\hline Februari & 2018 & 20 & 36 & 720 & 46 & $6,39 \%$ \\
\hline Maret & 2018 & 22 & 36 & 792 & 39 & $4,92 \%$ \\
\hline April & 2018 & 16 & 36 & 576 & 39 & $6,79 \%$ \\
\hline Mei & 2018 & 20 & 37 & 740 & 13 & $1,76 \%$ \\
\hline Juni & 2018 & 16 & 37 & 592 & 45 & $7,60 \%$ \\
\hline Juli & 2018 & 21 & 37 & 777 & 27 & $3,47 \%$ \\
\hline Agustus & 2018 & 22 & 37 & 814 & 42 & $5,16 \%$ \\
\hline September & 2018 & 19 & 37 & 703 & 30 & $4,27 \%$ \\
\hline Oktober & 2018 & 22 & 37 & 814 & 37 & $4,54 \%$ \\
\hline November & 2018 & 20 & 37 & 740 & 25 & $3,38 \%$ \\
\hline Desember & 2018 & 18 & 37 & 666 & 21 & $3,15 \%$ \\
\hline Rata-rata & & 19,75 & 36,6 & 722,41 & 33,91 & $4,77 \%$ \\
\hline
\end{tabular}

Sumber : KSP Tri Dharma Artha 2018.

Berdasarkan tabel diatas, terlihat bahwa absensi karyawan tertinggi terjadi pada bulan juni yaitu sebesar 7,60\% dan tingkat absen terendah terjadi pada bulan mei yaitu sebesar 1,76\%. Rata-rata tingkat absensi karyawan pada tahun 2018 sebesar 4,77\%, angka ini masih lebih tinggi dari batas yang ditolerir oleh KSP Tri Dharma Artha yaitu sebesar 3,50\%. Dalam hal ini penyebab ketidak hadiran karyawan adalah karena sakit, ada keperluan dan tanpa alasan yang jelas.

\subsection{Perumusan Masalah}

Berdasarkan latar belakang diatas maka penulis membuat perumusan masalah sebagai berikut :

Bagaimana pimpinan memberikan motivasi dan kedisiplinan kepada karyawan KSP Tri Dharma Artha Dikantor Pusat Seputih Raman? 


\subsection{Tujuan penelitian}

Berdasarkan dengan rumusan masalah yang dikemukakan oleh penulis untuk mengetahui bagaimana pimpinan memberikan motivasi dan kedisiplinan terhadap karyawan pada KSP Tri Dharma Artha.

\section{LANDASAN TEORI}

\section{Disiplin kerja}

Dalam suatu organisasi dan perusahaan pasti menginginkan adanya suatu disiplin Kerja yang tinggi darisetiap karyawan, karena dengan disiplin kerja yang tinggi Maka diharapkantercapainya prestasi kerja yang baik.

Menurut Hasibuan (2013:193)disiplin adalahkesadaran dan kesediaan Seseorang mentaati semua peraturan perusahaan dannorma-norma sosial yang Berlaku. SedangkanMenurut Rivai (2013:549) kinerja merupakan perilaku nyata Yang ditampilkan setiap orang sebagai prestasi kerja yang dihasilkan oleh Karyawan sesuai dengan perannya dalam perusahaan.

\section{Motivasi Kerja}

Motivasi sangat penting bagi seseorang mengingat motivasi merupakan dorongan atau motif dalam diri individu yang mempengaruhi tingkah laku tertentu, serta usahamenumbuhkembangkan kehidupan pribadi yang bersangkutan.Motivasi merupakan salah satu faktor penting untuk mencapai tujuan organisasi perusahaan.Motivasi membuat karyawan tetap mempunyai semangat kerja walaupun dihadapkan pada masalah-masalah sulit.Hal ini seperti yang dikatakan oleh Wexley \& Yukl (dalam Sutrisno, 2011) bahwa motivasi adalah sesuatu yang menimbulkan semangat atau dorongan kerja.Ini tidak jauh berbeda dari pendapat Robbins (dalam Sutrisno, 2011) bahwa motivasi merupakan suatu kerelaan berusaha seoptimal mungkin dalam mencapai tujuan organisasi yang dipengaruhi oleh kemampuan usaha memuaskan beberapa kebutuhan individu.

Menurut Rivai (2013:837) motivasi adalah serangkaian sikap dan nilai-nilai yang mempengaruhi individu untuk mencapai hal yang spesifik sesuai dengan tujuan individu.Sikap dan nilai tersebut merupakan suatu yang invisible yang memberikan kekuatan untuk mendorong individu bertingkah laku dalam arah perilaku (kerja untuk mencapai tujuan), dan kekuatan perilaku (seberapa kuat usaha individu dalam bekerja).

Menurut Hasibuan (2013:143) motivasi adalah pemberian daya penggerak yang menciptakan kegairahan kerja seseorang agar mereka mau bekerja sama, bekerja efektif, dan terintegrasi dengan segala daya upayanya untuk mencapai kepuasan. Dari defenisi di atas dapat dilihat bahwa motivasi merupakan hal yang penting untuk mendorong kinerja karyawan.

\section{Kinerja Karyawan}

Menurut Sutrisno (2011: 170) menjelaskan pada umumnya, kinerja diberi batasan sebagai kesuksesan seseorang di dalam melaksanakan suatu pekerjaan.Lebih tegas lagi Lawler dan Porter dalam Sutrisno (2011: 170), yang menyatakan bahwa kinerja adalah kesuksesan seseorang dalam 
melaksanakan tugas. Menurut Cormik dan Tiffin dalam Sutrisno (2011: 172) mengemukakan kinerja adalah kuantitas, kualitas, dan waktu yang digunakan dalam menjalankan tugas.Kuantitas adalah hasil yang dapat dihitung sejauh mana seseorang dapat berhasil mencapai tujuan yang telah di tetapkan.Kualitas adalah bagaimana seseorang menjalankan tugasnya, yaitu mengenai banyaknya kesalahan yang dibuat, kedisiplinan dan ketepatan.Waktu kerja adalah mengenai jumlah absen yang dilakukan, keterlambatan, dan lamanya masa kerja dalam tahun yang telah dijalani.

\section{METODE PENELITIAN}

\section{Jenis Penelitian}

Jenis penelitian dalam pengambilan data pada yang berhubungan dengan permasalahan yang terdapat pada penulisan ilmiah ini menggunakan dua cara :

1. Penelitian kepustakaan penelitian yang di lakukan dengan mengumpulkan data dan informasi berbagi literature dan tulisan ilmiah dari berbagai sumber yang dapat dipergunakan landasan teori dalam penulisan Tugas Akhir ini.

2. Penulisan lapangan penelitian yang di lakukan dengan mengadakan hubungan langsung dengan responden, yaitu dengan kuesioner.

\section{Metode Penelitian}

Penelitian ini merupakan penelitian kausal.Desain penelitian kausal dilakukan untuk menelaah varians dalam variabel terikat agar dapat memprediksi hasil dan keluarannya (output dan outcomes) yang bertujuan untuk mengetahui pengaruh disiplin dan motivasi kerja terhadap kinerja karyawan.

\section{Objek dan lokasi penelitian}

Yang menjadi objek penelitian pada tugas akhir ini adalah KSP Tri Dharma Artha yang beralamatkan di Seputih Raman Lampung Tengah.

\section{Populasi dan Sampel}

Populasi adalah keseluruhan subyek penelitian (Arikunto, 2002: 108). Berdasarkan pengertian tersebut, maka yang menjadi populasi dalam penelitian ini adalah karyawan pada KSP Tri Dharma Artha yang berjumlah 37 orang.

\section{Teknik Pengumpulan Data}

Studi Pustaka (Library Research)

Studi pustaka (library research) adalah studi yang dilakukan dengan membaca buku/literatur atau karya ilmiah lainnya dan sumber data lain yang mempunyai hubungan dengan penulisan penelitian ini.

Penelitian Lapangan (Field Research)

Penelitian lapangan (field research) dipergunakan untuk mendapatkan data primer langsung dari objek penelitian.Data primer adalah data yang langsung diperoleh dari sumber data. 


\section{Metode Analisis}

Analisis Kualitatif adalah analisis yang mengambarkan secara rinci melalui interprestasi terhadap data yang diperoleh melalui pendekatan teoritis. Untuk menyederhanakan data ke dalam bentuk yang mudah dipahami, maka semua data dari semua variabel dideskripsikan dalam bentuk tabulasi maupun persentase.

\section{HASIL DAN DAN PEMBAHASAN}

Berkaitan dengan hasil yang diteliti bahwa untuk meningkatkan kedisiplina dan motivasi karyawan KSP Tri Dharma Artha upaya yang dilakukan oleh pimpinan SDM Pusat yakni dengan dengan cara mendengarkan ide-ide baru dari karyawan seperti memberikan kesempatan bagi karyawan untuk mengembangkan pendapat melalui ide-ide baru dari karyawan, sebagai pimpinan harus fleksibel dalam menghadapi karyawan membangun kepercayaan untuk membrikan apresiasi sekali pun itu hal-hal kecil, serta memberikan bonus kepada karyawan saya yang rajin berupa uang dan terkadang juga memberi banus berupa uang tambahan atau reward, dan jika karyawan datang terlambat akan diberikan teguran, jika dengan teguran tetap seperti itu, maka mau tidak mau akan memberikan sanksi berat berupa surat peringatan.

Dalam meningkatkan motivasi karyawan agar lebih disiplin maka pimpinan memberikan reward atau bonus pada karyawan yang rajin dan disiplin dalam bekerja, atau diberi kesempatan oleh pihak perusahaan untuk berpendapat melalui ide-ide baru.

Kendala yang membuat karyawan kurang disiplin dalam bekerja adalah sangsinya kurang berat dan kurangnya ketegasan pada karyawan, jika pimpinan terlalu tegas maka karyawan akan semakin susah untuk dikendalikan untuk itu pimpinan harus fleksibel dalam menghadapi karyawan.

\section{SIMPULAN DAN SARAN}

\section{Kesimpulan}

Berdasarkan dari hasil penelitian diatas dapatdisimpulkan bahwa motivasimempengaruhi kedisiplinan karyawan,terlihat dari absensi karyawan tertinggi di bulan juni dan tingkat absensi terendah dibulan mei. Rata-rata tingkat absensi pada tahun 2018 masih tergolong tinggi, karena masih batas yang ditolerin oleh KSP Tri Dharma Artha.Penyebab ketidak hadiran karyawan adalah karena sakit, ada keperluan dan tanpa ada alasan yang jelas.Motivasi sangat penting bagi seseorang mengingat motivasi merupakan dorongan atau motif dalam diri individu yang mempengaruhi tingkah laku tertentu, serta usahamenumbuhkembangkan kehidupan pribadi yang bersangkutan.Motivasi merupakan salah satu faktor penting untuk mencapai tujuan organisasi perusahaan.Motivasi membuat karyawan tetap mempunyai semangat kerja walaupun dihadapkan pada masalah-masalah sulit. 
Karyawan dengan kinerja yang memuaskan merupaka asset perusahaan yang sangat berharga.Karyawan merupakan sumber daya manusia perusahaan yang sangat bernilai, serta dapat membantu dalam mencapai tujuan-tujuan perusahaan. Di dalam menjalankan roda suatu perusahaan, perusahaan harus memiliki karyawan yang mempunyai disiplin yang tinggi serta mempunyai motivasi kerja yang tinggi. Kinerja karyawan KSP Tri Dharma Artha di Kantor Pusat Seputih Raman juga dapat diukur melalui penyelesain tugasnya secara efektif dan efisien serta melakukan peran dan fungsinya sesuai tugas masing-masing.Kedisiplinan dan motivasi merupakan variabel penting yang dapat menentukan kinerja karyawan di suatu perusahaan.

\section{Saran}

Berdasarkan penilaian yang telah dilakukan, ada beberapa saran yang yang dapat digunakan sebagai bahan masukan dan pertimbangan bagi kemajuan perusahaan.

Adapun saran-saran yang diajukan, antara lain :

1. Perusahaan harus dapat merubah budaya disiplin di dalam dan di luar lingkungan perusahaan, mulai dari atasan hingga bawahan. Apabila disiplin di dalam perusahaan telah berjalan dengan baik, maka dapat meningkatkan disiplin kerja karyawan. Perusahaan dapat meningkatkan insentif berbentuk uang atau jabatan terhadap karyawan yang berprestasi sesuai dengan prestasi karyawan yang bersangkutan.

2. Perusahaan harus dpat meningkatkan motivasi kerja di lingkungan karyawan dengan memperhitungkan kebutuhan fisiologis seperti pemberian gaji, uang transportasi, uang makan dan sebagainya .penentuan pemberian kompensasi tergantung dari kontribusi presentase yang diberikan perusahaan.

3. Dalam meningkatkan kinerja karyawan, perusahaan dapat memberikan tugas yag menantang agar karyawan dapat mengembagkan kreativitas di dalam melakukan pekerjaan

\section{DAFTAR PUSTAKA}

Arikunto, Suharsimi. (2013). Prosedur Penelitian suatu pendekatan praktik.Bineka Cipta. Jakarta.

Fahmi, Iham. (2011). Manajemen Kinerja. Bandung: Alfabeta.

H. Moh . Kasiram,(2010). Metodologi Penelitian Kualitatif-Kuantitatif, Malang:UIN Maliki Press.

H.M. Burhan bungin,(2011). Penelitian Kualitatif Prenada Media Group, Jakarta.

Hasibuan, Malayu SP. (2013). Manajemen Sumber Daya Manusia: Dasar Kunci Keberhasilan. CV Haji Mas Agung. Jakarta.

Mangkunegara, A. P. (2010). Evaluasi Kinerja Manajemen Sumber Daya Manusia, Bandung: PT. Refika Aditama. 
Mangkunegara, A. P. (2010). Evaluasi Kinerja Manajemen Sumber Daya Manusia, Bandung: PT. Refika Aditama.

Rivai, V., \& Sagala, D. E. (2013).Manajemen Sumber Daya Manusia untuk Perusahaan, Jakarta: Rajawali Pers.

Romli, Khomsahrial. (2011). Komunikasi Organisasi Lengkap. Jakarta. Grasindo.

Suprihanto, John. (2008). Perilaku Organisasional. STIE YKPN. Yogyakarta.

Sutrisno, Edy.(2011). Manajemen Sumber Daya Manusia. Jakarta: Kencana Prenada.

Sutrisno, Edy.(2011). Manajemen Sumber Daya Manusia. Jakarta: Kencana Prenada. 